\title{
OTOLOGY
}

\section{Subtotal petrosectomy and cochlear implantation}

\author{
Petrosectomia subtotale e impianto cocleare \\ Giulia D’Angelo, Giulia Donati, Andrea Bacciu, Maurizio Guida, Maurizio Falcioni \\ Otorhinolaryngology and Otoneurosurgery Department, University Hospital of Parma, Italy
}

\section{SUMMARY}

Objective. The objective of this study is to analyse surgical outcomes in a series of patients who underwent subtotal petrosectomy in combination with cochlear implantation.

Methods. Retrospective chart review. Thirty patients (32 ears) underwent subtotal petrosectomy and cochlear implantation in one stage. Indications for subtotal petrosectomy included the following: cholesteatoma, chronic otitis media, previous canal wall-down, osteoradionecrosis, revision surgery for clinical reasons, inner ear malformations, middle ear anatomical variations and severe cochlear ossification.

Results. Follow-up ranged from 2 to 54 months. Only 2 complications related to the subtotal petrosectomy (1 subcutaneous abdominal haematoma and 1 subcutaneous abdominal seroma) occurred in this series. Complete electrode insertion was achieved in all but 4 cases. Conclusions. Subtotal petrosectomy is a safe procedure and can offer technical advantages in some cases of complex cochlear implantation.

KEY WORDS: cochlear implantation, subtotal petrosectomy, cholesteatoma, cochlear ossification, inner ear malformation

\section{RIASSUNTO}

Obiettivo. L'obiettivo dello studio è analizzare i risultati chirurgici in una serie di pazienti sottoposti a petrosectomia subtotale e impianto cocleare.

Metodi. Studio retrospettivo. Trenta pazienti (32 orecchie) sono stati sottoposti a petrosectomia subtotale e impianto cocleare, in unico tempo. Le indicazioni alla petrosectomia subtotale sono state le seguenti: colesteatoma, otite media cronica, precedente tecnica aperta, osteoradionecrosi, chirurgia di revisione per motivazioni cliniche, malformazioni dell'orecchio interno, varianti anatomiche dell'orecchio medio, e severa ossificazione cocleare.

Risultati. Il follow-up è compreso fra 2 e 54 mesi. Nella serie si sono verificate solo 2 complicanze correlate alla petrosectomia subtotale (1 ematoma addominale sottocutaneo e 1 sieroma addominale sottocutaneo). È stata ottenuta l'inserzione completa degli elettrodi in tutti i casi a parte 4.

Conclusioni. La petrosectomia subtotale è una procedura sicura che in alcuni casi complessi di impianto cocleare può offrire dei vantaggi tecnici.

PAROLE CHIAVE: impianto cocleare, petrosectomia subtotale, colesteatoma, ossificazione cocleare, malformazione dell'orecchio interno

\section{Introduction}

Cochlear implant (CI) has long been proven to provide hearing rehabilitation to patients with bilateral severe-to-profound sensorineural hearing loss ( $\mathrm{SN}$ HL) who do not benefit from traditional hearing aids.

In the majority of cases, the standardised transmastoid facial recess approach perfectly suits the surgical requirements, and surgical risks are fairly low ${ }^{1,2}$. However, cochlear implantation in complex situations (concomitant chronic otitis media with or without cholesteatoma, previous canal wall-down techniques, inner ear malformations with severe risk of cerebrospinal fluid leak, etc.) may be challenging ${ }^{1-5}$.
Received: June 16, 2020

Accepted: August 25, 2020

Correspondence

Giulia Donati

Azienda Ospedaliero-Universitaria di Parma, UOC Otorinolaringoiatria e Otoneurochirurgia, via Gramsci 14, 43126 Parma, Italy

Tel. +390521 703542. Fax +390521703788

E-mail: ju.donati@hotmail.it

\section{Funding}

None.

Conflict of interest

The Authors declare no conflict of interest.

How to cite this article: D'Angelo G, Donati G, Bacciu A, et al. Subtotal petrosectomy and cochlear implantation. Acta Otorhinolaryngol Ital 2020;40:450-456. https://doi. org/10.14639/0392-100X-N0931

(C) Società Italiana di Otorinolaringoiatria e Chirurgia Cervico-Facciale

\section{(c) $($ ) $\$$}

This is an open access article distributed in accordance with the CC-BY-NC-ND (Creative Commons Attribution-NonCommercial-NoDerivatives 4.0 International) license. The article can be used by giving appropriate credit and mentioning the license, but only for non-commercial purposes and only in the original version. For further information: https:// creativecommons.org/licenses/by-nc-nd/4.0/deed.en 
Subtotal petrosectomy (SP) was first described by Rambo in $1958{ }^{6}$ and then modified and popularised by Fisch in $1965^{7}$. The main steps of the procedure are: 1) blind sac closure of the external auditory canal (EAC); 2) exenteration of middle ear and mastoid, including perisigmoid, perilabyrinthine, perifacial and hypotympanic cells; 3) removal of middle ear epithelium and mucosa; 4) closure of tympanic orifice of the Eustachian tube; 5) and obliteration of the cavity with abdominal fat ${ }^{8}$. In 1998, Issing et al. and Bendet et al. ${ }^{9,10}$ proposed SP as the technique of choice for cochlear implantation in ears affected by chronic otitis media (COM). Over the past few years, SP has been progressively applied to a variety of difficult situations in CI surgery ${ }^{1-14}$, slowly overcoming the initial resilience of the majority of the CI surgeons.

In fact, through the closure of the tubal orifice and the EAC, SP permits complete isolation of the surgical cavity from the external environment, decreasing the risk of postoperative infection, cerebrospinal fluid (CSF) leakage and meningitis ${ }^{14,15}$. In addition, the unobstructed view and illumination of the surgical cavity provide an excellent control and visualisation of all available landmarks ${ }^{1,16}$. Finally, the wide angle of approach to the round window area, obtained by removing the postero-superior wall of the EAC, makes each manoeuvre during array insertion much easier. These advantages are particularly important in presence of surgical difficulties such as cochlear obliteration or distorted anatomy ${ }^{13,17}$.

The purpose of this study is to report our experience in a group of 30 patients who underwent SP combined with CI.

\section{Materials and methods}

A retrospective analysis of patients who underwent SP in combination with CI at the Department of Otorhinolaryngology and Otoneurosurgery of the University of Parma between January 2015 and March 2019 was performed. Subjects gave informed consent to the study and the study received the approval from the local Ethical Committee (Ref N. 36071). Patients requiring primary CI underwent complete otologic, audiologic, logopaedic and radiological examination (CT and MRI). Revision cases were only investigated by $\mathrm{CT}$ scan. Cochlear implantation was advised for standard indications, with no patients implanted for invalidating tinnitus and/or single side deafness. Data collected from patients' medical records included: demographic information, indication for SP, surgical time, intraoperative findings, electrophysiological data and postoperative complications, as well as clinical and radiologic follow-up findings. Follow-up was defined as the period of time from surgery to the most recent office visit. All patients but the
3 children were scheduled for a baseline control CT scan within 3 months from surgery. In patients with previous cholesteatoma or radical cavity (all adults), in which the risk of a cholesteatoma entrapment is higher, a new scan was planned at 3 years.

\section{Details of surgical technique}

The main concepts of the surgical technique have been described in previous publications ${ }^{1,18}$. A few significant refinements have been introduced and should be stressed because of their importance when combining SP with the positioning of a CI.

The standard retroauricolar skin incision should be extended supero-posteriorly for $2-3 \mathrm{~cm}$, in order to create the implant hosting pocket more posteriorly than in a standard case. This is very important because, after a SP, the development of a retroauricolar skin depression is very common even if without clinical significance in most of the cases. However, in presence of a CI, if the anterior margin of the receiver-stimulator is placed in correspondence of this depression, it can lead to extrusion (Fig. 1).

When performing the blind sac closure of the EAC, a second layer created by the posterior reflection of the tragal cartilage is strongly recommended. This helps to reinforce the closure and reduce the risk of connecting cable extrusion at this level. At the same time, it may limit the medial growth of the skin in case of a break-down of the first layer closure. An aggressive drilling of the anterior and inferior walls of the EAC is performed, especially at the level of the bony anulus, to minimise the possibility of leaving some skin debris at this level.

The facial ridge is lowered as much as possible to offer the best exposure of the round window niche. For this purpose,

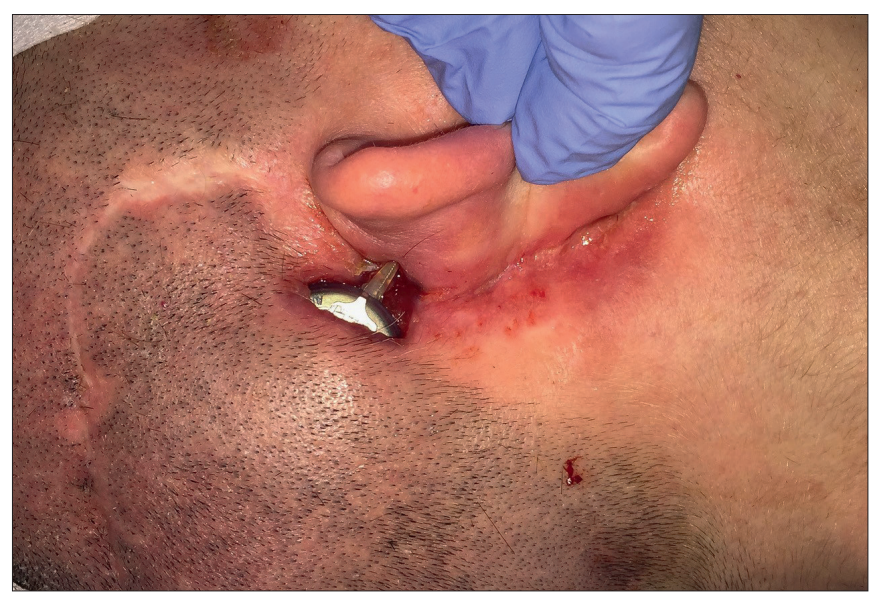

Figure 1. Extrusion of the receiver/stimulator in the area of the retroauricolar retraction. 
the removal of the bone anterior to the facial nerve is even more important. Unobstructed access to the round window niche represents one of the advantages of the SP and, especially in difficult cases, it must be maximised.

Drilling of the perilabyrinthine, hypotympanic, retrofacial and mastoid tip cells is accomplished. Residual mucosa is dissected or coagulated from these areas, as well as from the promontory and the tubal orifice, in order to avoid leaving any potentially infected tissue and/or the formation of mucous cysts/granulomas. At the end of the preparation, the cavity must be denuded by mucosa for the maximum extent (Fig. 2). In case of previous radical cavity or cholesteatoma, the same technique is applied to carefully remove all squamous epithelium, to avoid leaving skin debris with subsequent risk of inclusion cholesteatoma.

When the implant is finally in place, the connecting cable must be accommodated on the medial wall of the cavity and kept in place by the fat, in order to be maintained away from the subcutaneous layer. This reduces the risk of extrusion in the area where the aforementioned skin retraction will develop.

Whenever possible, the electrode array is inserted into the scala tympani (ST) through the round window membrane. In cases where the round window niche is not accessible (Fig. 3), a promontorial cochleostomy is performed. In presence of cochlear ossification, a first attempt to reach the ST is performed, drilling progressively the promontory in an antero-inferior direction, starting from the round window niche. If no cochlear lumen is visible, drilling is moved superiorly in order to locate the scala vestibuli (SV). When this latter is patent, a further attempt to open the ST is performed (2-3 mm) before taking the final decision (Fig. 4).

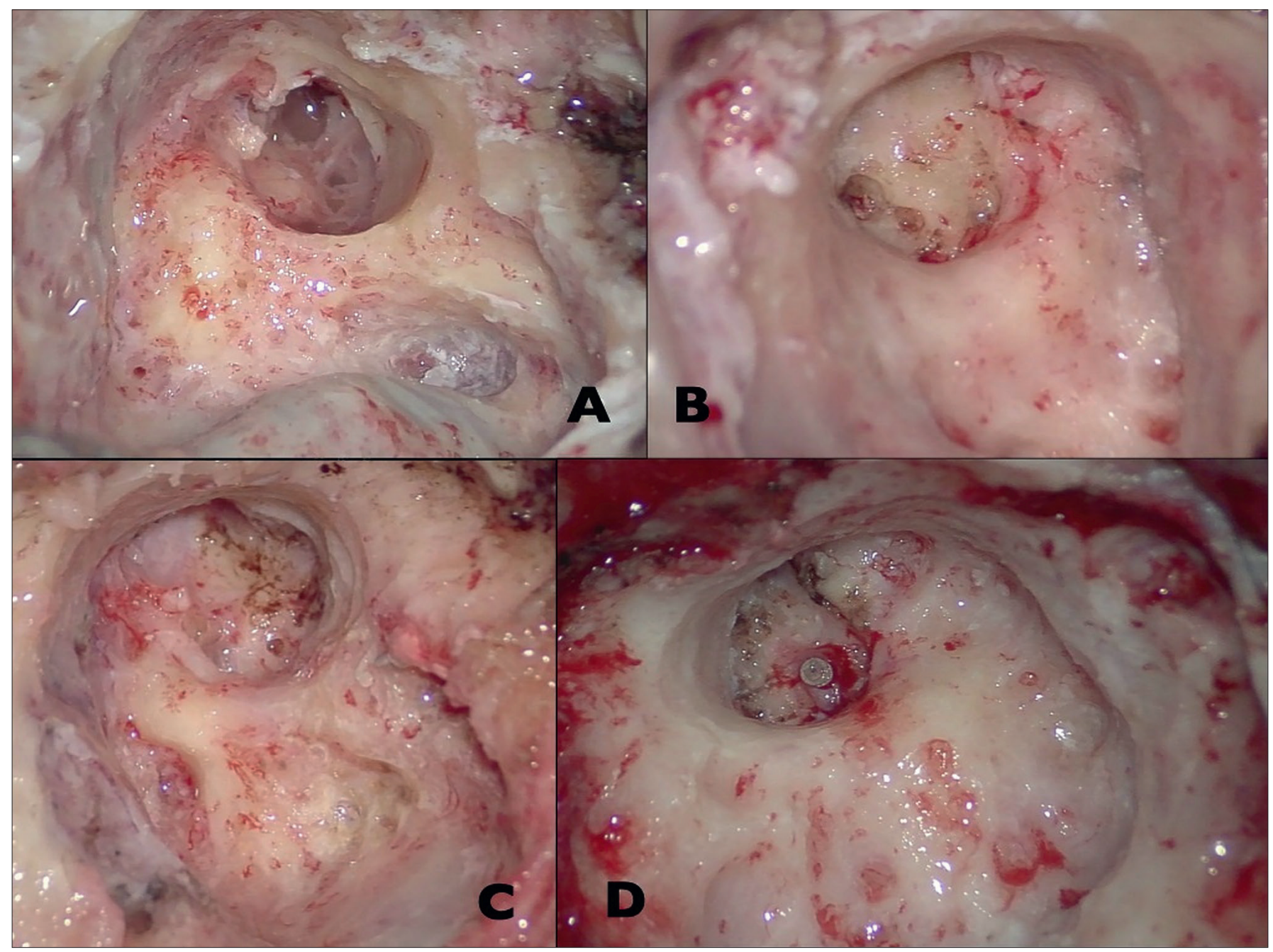

Figure 2. Final view of the bony cavity after cleaning of the pneumatisation and the mucosa (A, B, C, D - 4 different cases). 


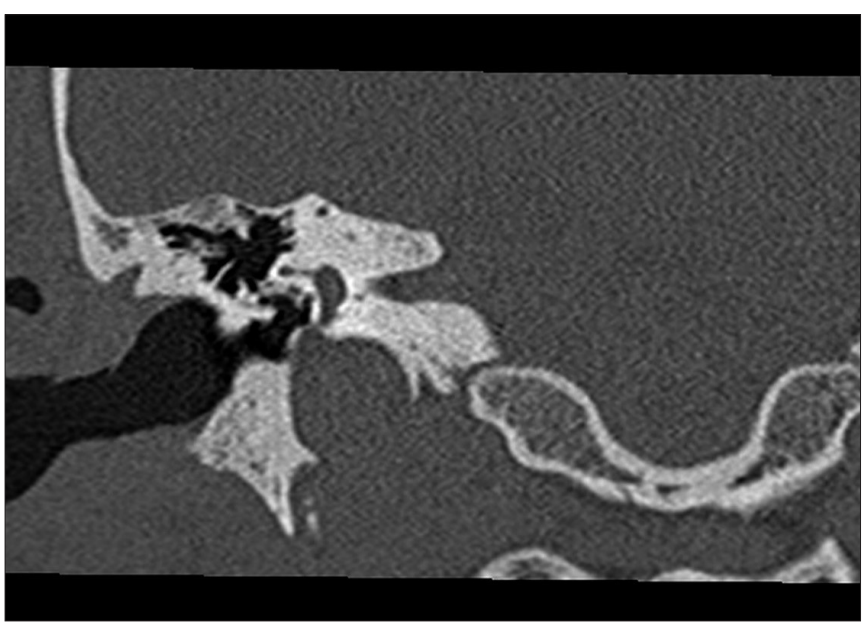

Figure 3. Coronal CT scan showing a superior protrusion of the jugular bulb covering completely the round window area; a promontorial cochleostomy had to be performed in order to reach the cochlear lumen.

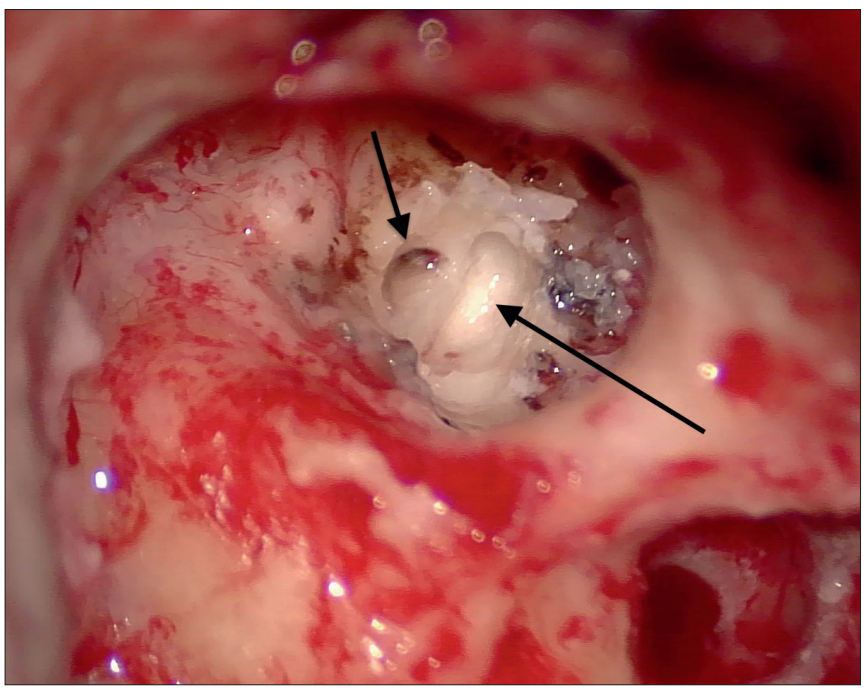

Figure 4. Intraoperative view of a severe cochlear ossification secondary to otosclerosis; after a promontorial drill-out, a cochlear lumen has been identified only at the level of the scala vestibuli (short arrow), while the scala tympani was completely ossified (long arrow).

\section{Results}

The study group was composed of 30 patients who underwent SP in combination with cochlear implantation as a single-stage procedure. Two patients were implanted bilaterally, resulting in a total of 32 surgically treated ears. Two additional cases ( 1 revision for complete array extrusion in an infected SP and 1 inner ear schwannoma) were excluded from the series because, intraoperatively, the cochlear drillout was considered too destructive to achieve sufficient hearing restoration, even if a probe was partially inserted (both of them had a normal cochlea on the contralateral side). In 3 cases the surgery was started as a standard transmastoid approach and an intraoperative switch to SP was required due to unpredicted difficulties.

The group included 19 female (63\%) and 11 male (37\%) patients. The right ear was involved in 14 cases (44\%), and the left ear in $18(56 \%)$. The mean age at the time of surgery was 49 years (range $4-78$ years). Of the 32 ears, 23 had already been operated at least once. Eleven ears already had a CI and were revision cases ( 9 previously treated in other centres). Among these, 9 were revision surgeries of a standard CI technique, 1 was a revision of a $\mathrm{CI}$ in a previous canal wall down and 1 was a revision of already a SP with CI. Table I shows the demographic characteristics, indications for SP and previous ear surgeries of the series. The indications for SP (sometimes multiple in the same patient) listed: cholesteatoma (10) (Fig. 5), chronic otitis media (3), previous radical cavity/canal wall-down mastoidectomies (4), severe cochlear obliteration (10), previous CI extrusion (2), previous extra-cochlear array positioning (1), anatomical variations (3), inner ear malformations (3), osteoradionecrosis (1).

All ears presented a preoperative pure tone average (PTA) $>90 \mathrm{~dB}$ with discrimination less than $10 \%$. In 26 cases, the hearing aid could not be used in the ear-to-be-implanted for audiological or clinical reasons (i.e. infection, previous blind sac closure of the EAC, large meatoplasty, etc.).

The Neurelec Digisonic SP device was used in 3 cases, the Oticon ZTI CLA in 10, the Oticon ZTI EVO in 1, the Nucleus CI 24 RE (ST) in 2 and the Nucleus CI 512 CA in the remaining 16.

Three ears were implanted into the scala vestibuli and the remaining 27 into the scala tympani. In 2 cases, due to severe ossification, it was not possible to clearly identify the scala in which the array was positioned.

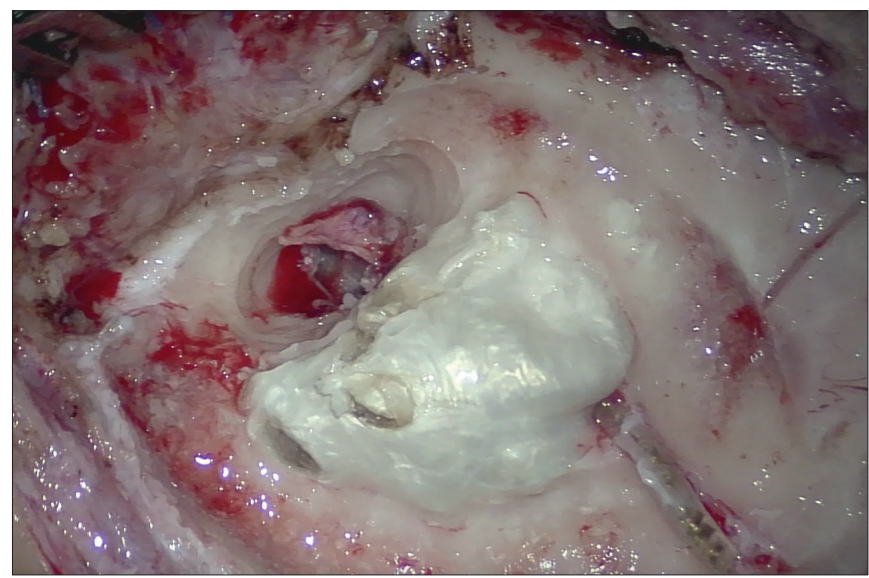

Figure 5. Extensive iatrogenic cholesteatoma secondary to a standard cochlear implantation. 
Table I. Demographic characteristics, previous ear surgeries and indications for SP of the series.

\begin{tabular}{|c|c|c|c|c|c|}
\hline Case & Sex & Age & Side & $\begin{array}{l}\text { Previous ipsilateral } \\
\text { ear surgery }\end{array}$ & Reason for SP \\
\hline 1 & M & 20 & $\mathrm{R}$ & NO & Malformation \\
\hline 2 & M & 73 & L & Stapedotomy, Cl & Cholesteatoma \\
\hline 3 & $\mathrm{~F}$ & 67 & L & Radical mastoidectomy & Previous radical cavity \\
\hline 4 & $\mathrm{~F}$ & 46 & L & NO & Anatomical abnormalities (high JB) \\
\hline 5 & M & 57 & L & CWD tympanoplasty, $\mathrm{Cl}$ & Previous CWD, array extrusion, ossification \\
\hline 6 & M & 62 & L & NO & Ossification \\
\hline 7 & M & 10 & $\mathrm{R}$ & NO & Anatomical abnormalities (high JB) \\
\hline 8 & M & 55 & $\mathrm{R}$ & Stapedotomy & Ossification \\
\hline 9 & $\mathrm{~F}$ & 5 & L & $\mathrm{SP}$ with $\mathrm{Cl}$ & Incomplete array insertion, malformation, CSF leak \\
\hline 10 & $\mathrm{~F}$ & 62 & $\mathrm{~L}$ & CWU tympanoplasty & $\mathrm{COM}$ \\
\hline 11 & $\mathrm{~F}$ & 63 & $\mathrm{R}$ & $\mathrm{Cl}$ & Cholesteatoma, \\
\hline 12 & $\mathrm{~F}$ & 71 & $\mathrm{~L}$ & Stapedotomy, Cl & Ossification, previous Cl malposition \\
\hline 13 & $\mathrm{~F}$ & 78 & $\mathrm{~L}$ & Stapedotomy, Cl & Cholesteatoma \\
\hline 14 & $\mathrm{~F}$ & 48 & R & $\begin{array}{l}\text { Cl with multiple revisions } \\
\text { (SP during last revision) }\end{array}$ & $\begin{array}{c}\text { Array and } \mathrm{Cl} \text { extrusion, blindsac closure breakdown } \\
\text { ossification }\end{array}$ \\
\hline 15 & $\mathrm{~F}$ & 59 & $\mathrm{R}$ & Stapedotomy and revision & Ossification \\
\hline 16 & $\mathrm{M}$ & 48 & L & CWD tympanoplasty and revisions & Previous CWD, ossification \\
\hline 17 & $\mathrm{~F}$ & 47 & L & CWU tympanoplasty and revision & Cholesteatoma, ossification \\
\hline 18 & $\mathrm{~F}$ & 37 & L & $\mathrm{SP}$ & Cholesteatoma, previous SP \\
\hline 19 & $\mathrm{~F}$ & 74 & $\mathrm{R}$ & NO & Cholesteatoma \\
\hline 20 & $\mathrm{~F}$ & 8 & L & $\mathrm{Cl}$ & Cholesteatoma, array extrusion \\
\hline 21 & $\mathrm{~F}$ & 69 & $\mathrm{R}$ & SP & Previous SP, cholesteatoma \\
\hline 22 & $\mathrm{~F}$ & 66 & $\mathrm{R}$ & $\mathrm{Cl}$ and revision with $\mathrm{SP}$ & Previous SP, ossification \\
\hline 23 & $\mathrm{~F}$ & 31 & $\mathrm{R}$ & NO & Ossification \\
\hline 24 & $\mathrm{M}$ & 42 & $\mathrm{R}$ & CWU tympanoplasty & Cholesteatoma \\
\hline 25 & $\mathrm{M}$ & 17 & $\mathrm{R}$ & $\mathrm{Cl}$, myringoplasty & $\mathrm{COM}$ \\
\hline 26 & $\mathrm{~F}$ & 72 & $\mathrm{R}$ & NO & Ossification, COM \\
\hline 27 & $\mathrm{~F}$ & 76 & $\mathrm{~L}$ & CWD tympanoplasty & Previous CWD, cholesteatoma \\
\hline 28 & $\mathrm{~F}$ & 56 & L & Stapedotomy & Ossification \\
\hline 29 & $\mathrm{~F}$ & 31 & L & $\mathrm{Cl}$ & Posterior wall erosion, ossification \\
\hline 30 & $\mathrm{M}$ & 63 & L & NO & Osteoradionecrosis \\
\hline 31 & M & 4 & L & NO & Malformation \\
\hline 32 & $\mathrm{~F}$ & 63 & $\mathrm{R}$ & Stapedotomy and revision & Ossification \\
\hline
\end{tabular}

M: male; F: female; R: right; L: left; Cl: cochlear implant; SP: subtotal petrosectomy; JB: jugular bulb; CWU: canal wall up; CWD: canal wall down; COM: chronic otitis media; CSF: cerebro-spinal fluid.

Full insertion of all the active electrodes was accomplished in 28 ears. In 3 patients the inserted electrodes were 18/20, 18/20 and $21 / 22$, respectively. In the last case, in spite of an aggressive drilling of the basal turn, only 10/22 electrodes were inserted because of severe post-labyrinthitis obliteration.

The median value of the surgical time for the non-revision cases was 172.5 minutes, with an IQR of 60 minutes. When compared with a homogeneous control group of standard $\mathrm{CI}$ interventions, performed by the same surgeon during the same period (median value $117.5 \mathrm{~min}, \mathrm{IQR} 48.75$ ), the difference was statistically significant ( $\mathrm{p} 0.0079$ ).

After surgery, 1 patient experienced a subcutaneous haematoma in the area of the fat harvesting, requiring surgical revision of the abdominal wound. Another patient developed a delayed seroma in the same area, treated with a simple aspiration in the office at the time of implant activation The follow-up of the series ranged from 2 to 54 months (mean, 22 months with a SD of 14 months). One patient died because of cardiological problems 1 year after the surgery, 3 patients are not daily implant users ( 2 of them are lost at follow up), while 3 additional patients are followedup in other centres near their hometown.

All patients but the children and the 2 lost to follow-up underwent the proposed radiological schedule. Presently, only 18 patients underwent a CT scan at 2 or more years after surgery. No residual cholesteatoma has been found to date. 
The CI was activated between 20 and 30 days after surgery. All patients but 3 had all the inserted electrodes active, confirming the intraoperative impression. There was a patient with no active electrodes; this was a revision case where a middle ear infection was complicated with a labyrinthitis leading to complete modiolus destruction; the patient did not experience any auditory sensation, despite a complete electrode insertion. Due to the extreme heterogeneity of the patients' group (children, comorbidities, periverbal patients, revision surgery, different length of follow-up, etc.) the audiological performances ranged from sound detection to $100 \%$ of discrimination.

\section{Discussion}

The indications for performing SP in combination with CI have been described by many authors in the literature ${ }^{1,2,9,18-22}$. Nowadays, most authors agree that CI combined with SP is the best surgical choice in deafened patients with chronic otitis media, cholesteatoma or/and previous cavity 1,4,5,16,23. In these situations, SP avoids disease recurrence and allows the creation of a closed and protected environment, significantly reducing the risk of infection and electrode array extrusion ${ }^{3,15}$. However, during the last years the scientific literature has documented a progressive increase in papers documenting the effectiveness of SP combined with cochlear implantation, even in patients with severe cochlear ossification/obliteration, inner ear malformations with high risk of CSF leak, fracture of the temporal bone with inner ear involvement and unfavourable anatomic conditions $1,2,9,10,13,16,17,19,21,24,25$. Some cases of revision surgery may also benefit from a larger and more comfortable approach. However, these indications are still not shared by all surgeons, probably because SP is not routinely performed in all otologic centres.

Most of the cases in our series presented more than one indication for adopting the technique. Under these circumstances, SP provides an excellent control of all the middle ear structures and, if required, offers the possibility to manage the carotid artery, the jugular bulb and, also, an anomalous course of the facial nerve. Unpredicted intraoperative difficulties may also suggest a switch from the classic approach to the SP, even if this increases surgical time.

The complete control of all the landmarks gives the possibility to perform safer surgical manoeuvres ${ }^{1,6}$. In particular, a better control of the round window area may increase the possibility of a correct and complete insertion even in presence of complex cases ${ }^{8,12,16}$.

This was confirmed in our series by the absence of extracochlear array positioning and the high rate of electrodes insertion (only 4 cases of incomplete insertion). Even in all the otosclerosis cases, in spite of an aggressive drill-out of the basal turn, a complete electrode array insertion was possible in $100 \%$ of the patients.

The price to pay for these advantages is represented by the necessity of an additional abdominal incision with the consequent risk of complications ( 1 subcutaneous haematoma and 1 seroma in our series). These were the only complications directly connected to the surgical technique (the other was atrial fibrillation in a cardiopathic patient). However, these results may be achieved only if the technique is meticulously performed in every step, as confirmed by 3 patients in the series that had already undergone a SP (1 with and 2 without a simultaneous $\mathrm{CI}$ ) and required revision surgery.

Another criticism of the technique is the prolonged surgical time, which was significant longer ( $p$ 0.0079) compared to standard CI interventions; however, the difference can be justified, at least partially, by the complexity of the SP cases. There is general consensus that SP and CI can be safely performed simultaneously in the majority of the cases ${ }^{1,12,16}$. It is still debated whether, in active purulent COM, cholesteatoma and previous cavity, SP should precede CI of several months (6 to 12), as recommended by most authors ${ }^{3,9,21,22}$. This staging strategy can reduce the risk of meningitis resulting from the insertion of an electrode in a potentially contaminated field ${ }^{1,22}$ and reduce the risk of residual cholesteatoma. In agreement with other authors ${ }^{2}$, we usually prefer to perform SP and CI in a single stage. We believe that SP usually permits a macroscopic total squamous epithelium and infected tissue removal, facilitated by the wide exposure. In addition, the staged strategy introduces a significant delay in the hearing rehabilitation process. We recommend a two-stage procedure only for special cases with surgical impression of incomplete disease removal (never encountered till now). In the osteoradionecrosis case included in the series, being the patient affected by bilateral occlusion of 2 carotid stents (100\% and 50\%), the infective risk was judged inferior of that of an additional surgery.

In most cases (without cholesteatoma or previous cavity) where the technique is correctly performed, the risk of skin entrapment is so low that, in our opinion, does not require a radiological follow-up. A CT scan is usually acquired within 3 months after surgery (not in children), and can be used as baseline in case a further investigation is required in the future.

In presence of radical cavity or COM with cholesteatoma, despite all efforts to meticulously remove all squamous epithelium, residual cholesteatoma can occur even many years after surgery ${ }^{1,3,10,15}$. Hence, prolonged follow-up in these patients is necessary. The most adopted protocol is 
to follow the patients with a CT every 2 or 3 years for 10 years. Diffusion-weighted non-EPI MRI, which is considered the gold standard evaluation for residual cholesteatoma, is completely useless in the presence of a CI, because of the huge artefacts produced by this specific sequence. However, all the new generation implants allow the magnet to be removed and repositioned under local anaesthesia, immediately before and after the MRI. This procedure may be scheduled once (after 3 or 4 years), in order to stop any further evaluation. Even if the follow-up it too short to reach definitive conclusions, we have not recorded a single cholesteatoma entrapment to date.

\section{Conclusions}

The SP approach may be safely adopted in cochlear implantation surgery when facing a variety of difficult situations. Its adoption is strongly recommended in presence of cholesteatoma, chronic otitis or a previous cavity. In other situations, even if not mandatory, it may help in reducing clinical failures and partial insertions. The mean additional surgical time required, compared to the standard transmastoid approach, applied to uncomplicated cases, is around one hour. In order to reach these goals and avoid complications, the technique must be mastered perfectly in every single detail. Even if not adopted with the frequency reported in our series, we believe it should be part of the technical expertise/skill of every surgeon performing cochlear implants. The suggested strategy of staging seems not necessary if only in exceptional cases.

\section{References}

1 Free RH, Falcioni M, Di Trapani G, et al. The role of subtotal petrosectomy in cochlear implant surgery - a report of 32 cases and review on indications. Otol Neurotol 2013;34:1033-40. https://doi. org/10.1097/MAO.0b013e318289841b

2 Bernardeschi D, Nguyen Y, Smail M, et al. Middle ear and mastoid obliteration for cochlear implant in adults: indication and anatomical results. Otol Neurotol 2015;36:604-9. https://doi.org/10.1097/ MAO.0000000000000702

3 Pasanisi E, Vincenti V, Bacciu A, et al. Multichannel cochlear implantation in radical mastoidectomy cavities. Otolaryngol Head and Neck Surg 2002;127:432-6. https://doi.org/10.1067/mhn.2002.129822

4 Hunter JB, O'Connell BP, Wanna GB. Systematic review and metaanalysis of surgical complications following cochlear implantation in canal wall down mastoid cavities. Otolaryngol Head Neck Surg 2016;155:555-63. https://doi.org/10.1177/0194599816651239

5 Sanna M, Dispenza F, Falcioni M, et al. Management of chronic otitis by middle ear obliteration with blind sac closure of the external auditory canal. Otol Neurotol 2008;29:19-22. https://doi.org/10.1097/ MAO.0b013e31815dbb40

6 Rambo, JHT. Primary closure of the radical mastoidectomy wound: a technique to eliminate postoperative care. Laryngoscope 1958;68:1216-27. https://doi.org/10.1002/lary.5540680707

7 Fisch U. Microsurgery of the temporal bone. HNO 1977;25:193-7.
8 Coker NJ, Jenkins HA, Fisch U. Obliteration of the middle ear and mastoid cleft in subtotal petrosectomy: indications, technique, and results. Ann Otol Rhinol Laryngol 1986;95:5-11. https://doi. org/10.1177/000348948609500102

9 Issing PR, Shönermark MP, Winkelmann S, et al. Cochlear implantation in patients with chronic otitis: indications for subtotal petrosectomy and obliteration of the middle ear. Skull Base Surg 1998;8:127-31. https://doi.org/10.1055/s-2008-1058571

10 Bendet E, Cerenko D, Linder TE, et al. Cochlear implantation after subtotal petrosectomies. Eur Arch Otorhinolaryngol 1998;225:16974. https://doi.org/10.1007/s004050050037

11 Adunka OF, Buchman CA. Cochlear implantation in the irradiated temporal bone. J Laryngol Otol 2007;121:83-6. https://doi. org/10.1017/S0022215106002180

12 Prasad CS, Roustan V, Sanna M, et al. Subtotal petrosectomy: Surgical technique, indications, outcomes, and comprehensive review of literature. Laryngoscope 2017;127:2833-42. https://doi.org/10.1002/lary.26533

13 Vashishth A, Fulcheri A, Prasad SC, et al. Cochlear implantation in cochlear ossification: retrospective review of etiologies, surgical considerations, and auditory outcomes. Otol Neurotol 2018;39:17-28. https://doi.org/10.1097/MAO.0000000000001613

14 Merkus P, Free RH, Mylanus EA, et al. Dutch Cochlear Implant Group (CI-ON) consensus protocol on postmeningitis hearing evaluation and treatment. Otol Neurotol 2010;31:1281-6. https://doi. org/10.1097/MAO.0b013e3181f1fc58

15 Vincenti V, Pasanisi E, Bacciu A, et al. Long-term results of external auditory canal closure and mastoid obliteration in cochlear implantation after radical mastoidectomy: a clinical and radiological study. Eur Arch Otorhinolaryngol 2014;271:2127-30. https://doi.org/10.1007/s00405-013-2698-3

16 Polo R, Del Mar Medina M, Arístegui M, et al. Subtotal petrosectomy for cochlear implantation: lessons learned after 110 cases. Ann Otol Rhinol Larynngol 2016;125:485-94. https://doi. org/10.1177/0003489415620427

17 Roland JT Jr, Coelho DH, Pantelides H, et al. Partial and double-array implantation of the ossified cochlea. Otol Neurotol 2008;29:1068-75. https://doi.org/10.1097/MAO.0b013e318188e8ea

18 Sanna M, Free R, Merkus P, et al. Surgery for cochlear and other auditory implants. First Edition. Stuttgart: Thieme; 2015.

19 Arndt S, Beck R, Shild C, et al. Management of cochlear implantation in patients with malformations. Clin Otolaryngol 2010;35:220-7. https://doi.org/10.1111/j.1749-4486.2010.02124.x

20 Sennaroglu L. Cochlear implantation in inner ear malformations a review article. Cochlear Implants Int 2010;11:4-41. https://doi. org/10.1002/cii.416

21 Leung R, Briggs RJ. Indications for and outcomes of mastoid obliteration in cochlear implantation. Otol Neurotol 2007;28:330-4. https:// doi.org/10.1097/01.mao.0000265187.45216.71

22 Szymański M, Ataide A, Linder T. The use of subtotal petrosectomy in cochlear implant candidates with chronic otitis media. Eur Arch Otorhinolaryngol 2016;273:363-70. https://doi.org/10.1007/s00405-015-3573-1

23 Ketelslagers K, Somers T, De Foer B, et al. Results, hearing rehabilitation, and follow-up with magnetic resonance imaging after tympanomastoid exenteration, obliteration, and external canal overclosure for severe chronic otitis media. Ann Otol Rhinol Laryngol 2007;116:70511. https://doi.org/10.1177/000348940711600914

24 Balkany T, Bird PA, Hodges AV, et al. Surgical technique for implantation of the totally ossified cochlea. Laryngoscope 1998;108:988-92. https://doi.org/10.1097/00005537-199807000-00007

25 Greenberg SL, Shipp D, Lin VY, et al. Cochlear implantation in patients with bilateral severe sensorineural hearing loss after major blunt head trauma. Otol Neurotol 2011;32:48-54. https://doi.org/10.1097/ MAO.0b013e3181ff73fd 